\title{
Grub-like larvae of Neuroptera (Insecta): a morphological review of the families Ithonidae and Polystoechotidae and a description of Oliarces clara
}

\author{
VASILY V. GREBENNIKOV \\ Institut für Spezielle Zoologie und Evolutionbiologie, Friedrich-Schiller-Universität Jena, Erbertstraße 1, D-07743 Jena, Germany \\ and Department of Zoology and Entomology, University of Pretoria, Pretoria 0002, South Africa; e-mail: v_grebennikov@mail.ru
}

Key words. Oliarces, Ithone, Polystoechotes, Ithonidae, Polystoechotidae, Neuroptera, larva, description, morphology, phylogeny

\begin{abstract}
First instar larvae of Polystoechotidae sp., and first and older instar larvae of Ithone fusca Newman and Oliarces clara Banks are described; those of the latter species for the first time. The family Ithonidae is unique in Neuroptera in having grub-like $\mathrm{C}$-shaped older instar larvae. Potential morphological synapomorphies of mature larvae of Ithonidae and Polystoechotidae are the mandibles with exceptionally broad base and markedly thickened apical part; antennal curvature is fixed and rather characteristic in shape; ocular area reduced or absent; cardo and stipes are markedly enlarged with stipes much larger than the cardo; presence of gula (Polystoechotes) or some traces of gular sclerotisation (Ithone, Oliarces). Larvae of Ithone have numerous larval autapomorphies such as C-shaped first instar larva with reduced abdominal segments IX and X; fused tibia and tarsus on all legs and dorsally directed maxillae. Larvae of Ithonidae and Polystoechotidae have some similarities with those of the family Dilaridae, such as no or one pair of stemmata; body not flattened dorso-laterally; mesothoracic spiracle located on fold between prothorax and mesothorax; short and stout mandibles widened at base and tapered apically; robust and elongated fore legs; tarsi on all legs markedly shortened; more than three larval instars. Older instar larvae of Ithonidae are markedly similar to those of the beetle superfamily Scarabaeoidea in having a C-shaped body, at least in older instars; body round in cross-section; sclerites on thorax and abdomen reduced and body surface membranous; each thoracic and abdominal segment subdivided dorsally into two or three fleshy lobes; ventral surface of abdominal apex bears a field of short and stout setae. Chaetotaxy pattern in first instar Ithonidae and Polystoechotidae larvae suggests that it is possible to homologise the sensilla in different genera and provide a system of sensilla designation for Neuroptera larvae. This study is illustrated with 36 morphological drawings.
\end{abstract}

\section{INTRODUCTION}

The neuropteran families Ithonidae and Polystoechotidae are believed to be closely related and together with Rapismatidae form a sister group to the rest of the Hemerobiiformia clade (Aspöck, 1993, 2002; Aspöck et al., 2001). Rapismatidae is a small family from the highlands of the Oriental region (Barnard, 1981) and its immature stages are unknown. The remaining two families are also relatively small and include together some 20 species. The family Polystoechotidae is restricted to the New World and is represented by four species arranged in three genera: Fontecilla graphicus Navás, 1932 and Polystoechotes gazullai Navás, 1924 from Chile, Platystoechotes lineatus Carpenter, 1940 from California, USA and Polystoechotes punctatus (Fabricius, 1793) widely distributed from Panama to southern Canada (Oswald, 1998). The family Ithonidae includes three genera from Australia and Tasmania and two from Northern and Central America: Ithone Newman, 1838 with 10 species in southern and eastern Australia and Tasmania (Riek, 1974), Megalithone Riek, 1974 with two species in southeastern Australia (Riek, 1974), Varnia Walker, 1869 with two species from inland and south-western Australia (Riek, 1974), monotypic Oliarces Banks, 1908 with $O$. clara Banks, 1908 from western USA (another apparently new species of Oliarces is known from Baja California, Mexico; David Faulkner, personal communication) and recently described monotypic Adamsiana Penny, 1996 with A. curoei Penny, 1996 from Honduras (Penny, 1996).

Tillyard (1922) described the highly unusual larvae of Ithone fusca Newman, 1838, which look very much like grubs of fruit-chafers or June beetles (subfamilies Cetoniinae and Melolonthinae of the beetle family Scarabaeidae). Other similar looking larvae are unknown within the superorder Neuropterida and the unusual appearance of Ithone larvae have puzzled subsequent researchers. It was originally believed that the grubshaped larva of Ithone were predatory, like the rest of the Neuropterida. Tillyard (1922: 222) firmly believed that larvae of Scarabaeidae are a food source for Ithone larvae and he vividly described his experiments on Ithone feeding behaviour. He suggested that Ithone larvae, whose mandibles are directed markedly upwards, approach their prey from beneath, strike them from below and suck them dry. As for Polystoechotidae, Welch (1914) described the first instar larvae of Polystoechotes punctatus and like Tillyard suggested that "it seems safe to call this a predaceous larva..." (Welch, 1914: 5). Unlike C-shaped Ithone, the first instar larva of Polystoechotes is of "campodeiform" (or "carabaeiform") shape. Currently, however, it is generally accepted that larvae of Ithonidae (Faulkner, 1990) and Polystoechotidae are in fact phytophagous, which is unique within Neuropterida and is the only synapomorphy linking these two families (Aspöck et al., 2001). Withycombe (1925) provided larval re-descriptions for these two species. 
MacLeod (1964) in his unpublished PhD thesis described and compared the morphology of the head capsule and cervix of mature larvae of $P$. punctutatus and I. fusca; the former is the only information on older instar Polystoechotidae larvae. These publications were the only original sources of information on the larval morphology of the Neuropteran families Ithonidae and Polystoechotidae.

My interest in the peculiarly shaped larvae of Ithonidae originated during research on mainly grub-like larvae of Scarabaeoidea (Grebennikov et al., 2002, 2004; Grebennikov \& Scholtz, 2004; Scholtz \& Grebennikov, 2004) and Dascillidae (Grebennikov \& Scholtz, 2003). Originally I wondered how many similar larval characters could have developed independently in similar, but unrelated larvae of Scarabaeoidea (Coleoptera) and Ithonidae (Neuroptera). When reading about Ithonidae larvae, I became aware that David Faulkner had obtained larvae of the Californian ithonid Oliarces clara and that the older instars of this species are also characteristically grubshaped. Through the kindness of D. Faulkner, I was able to borrow these unique Oliarces larvae, describe them and compare them with those of Ithone and a representative of the family Polystoechotidae. The result is the present paper with the aims to describe the morphology of first- and older instar larvae of Oliarces clara and redescribe that of Ithone fusca and a representative of the family Polystoechotidae; to discuss possible larval synapomorphies for the families Ithonidae and Polystoechotidae; and to compare convergent similarities between grub-shaped larvae of Ithonidae (Neuroptera) and Scarabaeoidea (Coleoptera).

\section{MATERIAL AND METHODS}

Larvae for the study were first disarticulated and cleaned in a hot water solution of $\mathrm{KOH}$. Older instar larvae were impregnated in glycerol and studied under dissecting and compound microscopes at a magnification of up to $\times 900$. First instar larvae were mounted on microscope slides in Euparal or Hoyer's medium and studied under a compound microscope. Drawings were made with the aid of a camera lucida. For the genera Ithone and Oliarces I was able to study first instar and mature larvae, while for those of the family Polystoechotidae only first instar larvae were available. I was unable to locate the two mature larvae of $P$. punctatus in the National Museum of Natural History (Washington D.C., USA), which MacLeod studied, and therefore had to rely on his unpublished thesis (1964) in order to compare them with the mature larvae of Ithonidae. The concept of Neuroptera families follows that of Tauber (1991) and Aspöck et al. (2001).

\section{LARVAE OF ITHONIDAE AND POLYSTOECHOTIDAE}

\section{Diagnosis}

First instar larvae. Like older instars, except in general appearance, which is C-shaped (Ithone) or carabaeiform (Oliarces, Polystoechotidae); dorsal fleshy lobes on thorax and abdomen absent; cranium not or only slightly (Ithone) retracted into prothorax; abdominal segments IX and X normal (Oliarces, Polystoechotidae) or markedly (Ithone) reduced; larvae with symmetrical chaetotaxy; ventral surface of abdominal segment IX without field of short and stout setae. Older instar larvae (description is only for the family Ithonidae; for information on P. punctatus see MacLeod, 1964). Grub-like C-shaped larvae, resembling those of the beetle family Scarabaeidae. Colour creamy-whitish. Chaetotaxy differs markedly from that in first instar. Cranium prognathous and retracted into prothorax up to about half length; without apodemae or visible sutures; labrum completely fused with dorsal cranial surface forming frontale with concave toothless anterior edge; stemmata absent. Antennae not pointed apically; located mediad from dorsal mandibular articulation on dorsal surface of cranium; about as long as labial palps and slightly shorter than mandibles or maxillae; attached to cranium by membranous hemispheric antennifer; apical part of penultimate antennomere with flat and oval sensorium located ventro-medially; antennae with setae only on 2 apical antennomeres. Mandible straight, with wide base and pointed apex forming, together with markedly larger maxillae, a sucking apparatus. Cardines forming the large plate of ventral surface of structural head. Lateral parts of mesothorax separated into 2 fleshy lobes with mesothoracic spiracle located on the anterior lobe. Thorax with 3 pairs of well-developed legs; fore legs slightly (Oliarces) or markedly (Ithone) larger than middle- and hind legs; tarsi reduced in length, free (Oliarces) or fused with tibia (Ithone); 2 well-developed claws without setae; 2 claw setae located on small sclerite located ventrally between base of each claw; empodium absent. Abdomen with abdominal segments I-VIII well developed; segments I-V subdivided into 2 (Oliarces) or 3 (Ithone) fleshy lobes; segment IX reduced in size; segment X absent. Ventral surface of abdominal segment IX with field of short and stout setae. Abdomen terminates with a small rounded projection on posterior surface of segment IX. Annular spiracles present on mesothorax and abdominal segments I-VIII.

\section{Ithone fusca Newman, 1838 \\ Description}

First instar larva (Figs 18-22): Head width: $0.46 \mathrm{~mm}$ $(\mathrm{n}=1)$. Dorsal surface of cranium with 2 large setae posteriorly, near median line (Fig. 19); cardo with 1 lateral seta; antennae, in addition to the basal and 2 apical antennomeres, with 2 smaller antennomeres between them. Final instar larva (Figs 1-8): Head width: $1.75 \mathrm{~mm}(\mathrm{n}=$ 1); larva more elongated and slender (Fig. 1) than that of Oliarces; metathorax dorsally with markedly developed transverse separation into smaller anterior and larger posterior lobes (Fig. 1); abdominal segments $\mathrm{I}-\mathrm{V}$ with 3 fleshy lobes (Fig. 1); mesothoracic spiracle about 4-6× larger and first abdominal spiracle 2-3× larger than other abdominal spiracles (Fig. 1); spiracles markedly larger and elongated, their greatest length not less that $2 \times$ longer than width (Fig. 1); cranium not flattened dorso-ventrally (Fig. 8); legs markedly larger (Fig. 1); posterior claws $0.6-0.8 \times$ of size of anterior claw (Figs 3,4$)$; tarsus and tibia completely fused (Figs 3,4); combined length of fused tibia and tarsus about half length of femur (Fig. 4); cranium and legs with numerous setae (Figs 3-8); dorsal 

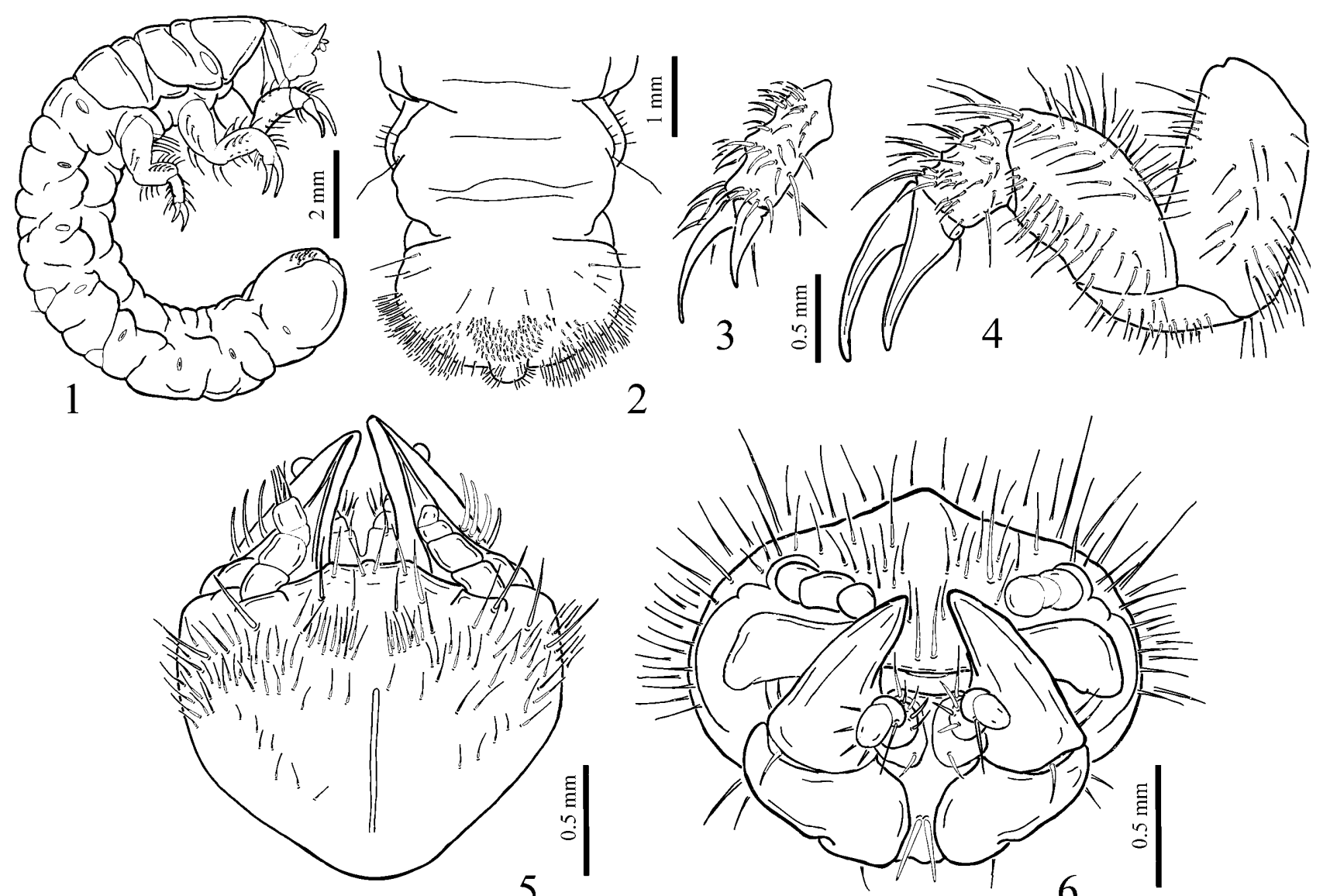

2
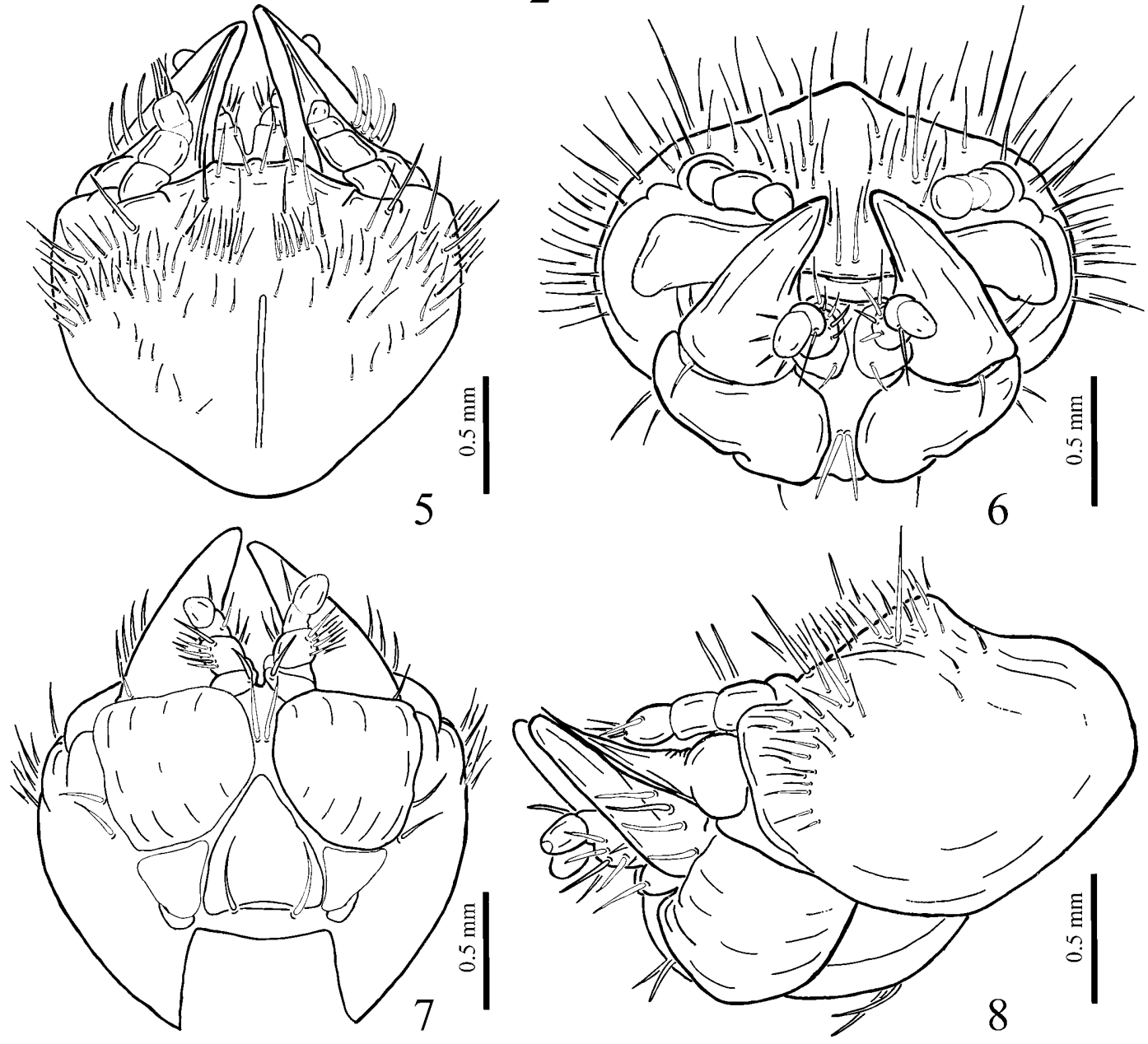

Figs 1-8: Ithone fusca, older instar larva. 1 - habitus, lateral; 2 - seventh and eighth abdominal segments, ventral; 3 - hind leg, posterior; 4 - fore leg, posterior; 5 - head, dorsal; 6 - head, frontal; 7 - head, ventral; 8 - head, lateral.

surface of body covered with numerous short setae; abdominal segment VIII and IX fused (Figs 1, 2); apical part of abdomen as wide as middle of abdomen (Fig. 1).

Material examined. One pupa, 2 old, 1 intermediate and 4 first instar larvae with the label: "not fixed Woy Woy, Feb. 09, 1918, ex. coll R.J. Tillyard" (Natural History Museum, London), of them 1 old, 1 intermediate and 1 first instar larva mounted on two microscope slides. Remarks. I also studied one older or intermediate larva of an unidentified species of Ithone with the following label: Australia, South Australia, Mt. Gambier, ex pine forest soil, May 1967, P. de Vries leg., T.A. Weir det. (Australian National Insect Collection). This larva is similar in detail to that of Ithone fusca.

\section{Oliarces clara Banks, 1908 \\ Description}

First instar larva (Figs 23-29): Head width: $0.34 \mathrm{~mm}$ $(\mathrm{n}=1)$. Dorsal surface of cranium without 2 large setae posteriorly, near median line (Fig. 24); cardo with 2 lateral setae; antennae, in addition to the basal and 2 apical antennomeres, with 3 smaller antennomeres between them. Final instar larva (Figs 9-17): Head width: 1.35 $\mathrm{mm}(\mathrm{n}=1)$; larva less elongated and less slender (Fig. 9) than that of Ithone; meso- and metathorax dorsally complete, or with vestigial transverse separation into anterior and posterior lobes (Fig. 9); abdominal segments I-V 

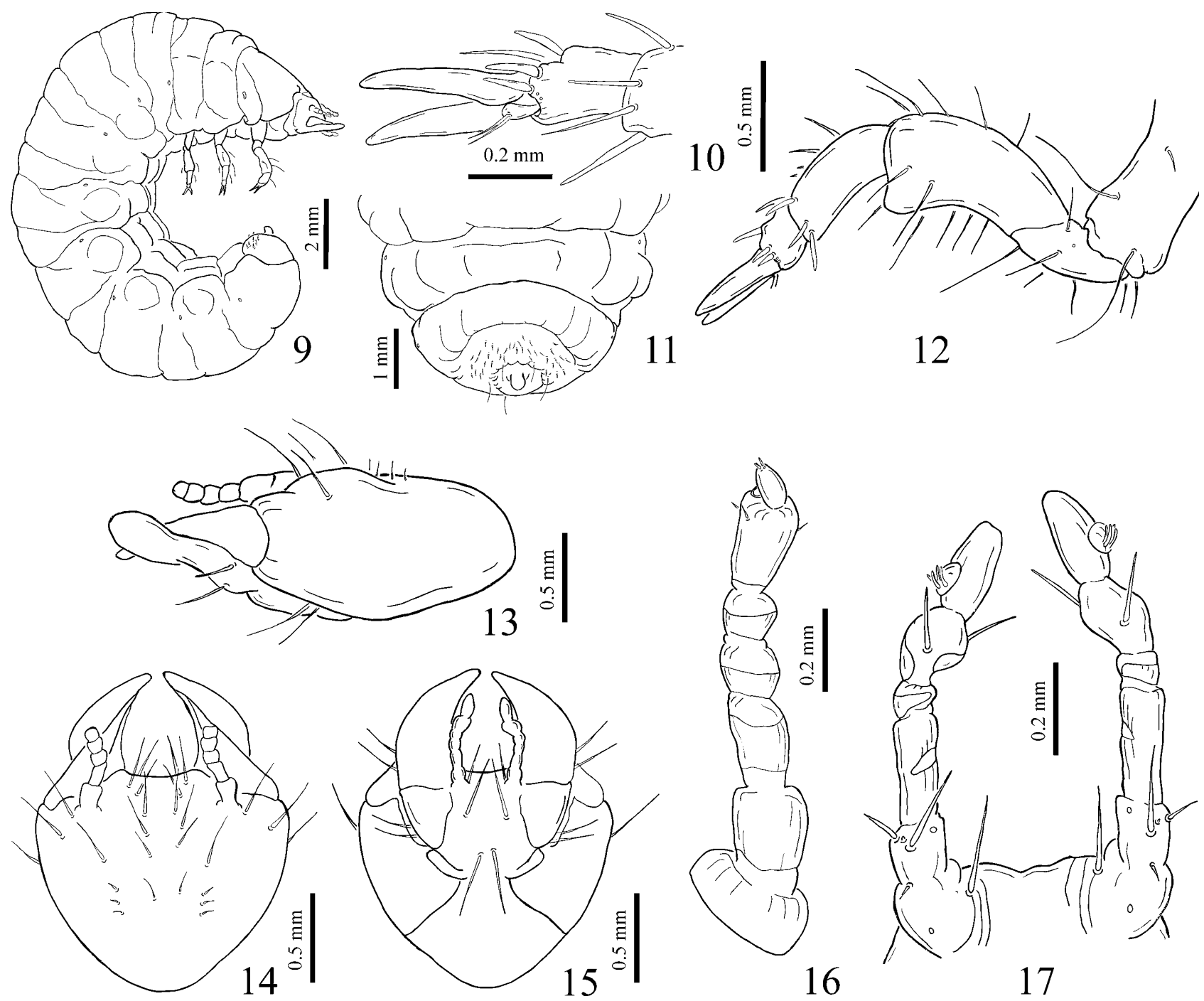

Figs 9-17: Oliarces clara, older instar larva. 9 - habitus, lateral; 10 - apex of tibia, tarsus and claws, fore leg, posterior; 11 - seventh and eighth abdominal segment, ventral; 12 - fore leg, posterior; 13 - head, lateral; 14 - head, dorsal; 15 - head, ventral; 16 right antenna and antennifer, dorsal; 17 - labial palps, ventral.

with 2 fleshy lobes (Fig. 9); mesothoracic spiracle about $2 \times$ larger and first abdominal spiracle $1.5 \times$ larger than other abdominal spiracles (Fig. 9); spiracles markedly smaller and not elongated, their greatest length not more than $1.5 \times$ longer than width (Fig. 9); cranium flattened dorso-ventrally (Fig. 13); legs markedly smaller (Fig. 9); claws of equal size (Figs 10,12); tarsus and tibia separated by suture (Fig. 12); combined length of separate tibia and tarsus about as long as femur (Fig. 12); cranium and legs with few setae (Figs 12-15); dorsal surface of body without setae; abdominal segment VIII and IX separated (Fig. 9); apical part of abdomen markedly narrower than middle of abdomen (Fig. 9).

Material examined. Four first instar larvae: USA: California, Riverside, Palm Desert Highlands, Collected Apr. 29, 1964; hatched June 05, 1964 R.J. Lyon (2 larvae mounted on microscope slide), D.K. Faulkner det. (Natural History Museum, London). Four older instar larvae: USA: California, Imperial Co., Chocolate Mnt., Black Mnt., Dec. 09, 1984, D.K. Faulkner leg., det. (author's collection).

\section{Polystoechotidae sp. \\ Description}

First instar larva (Figs 30-36): Head width: $0.56 \mathrm{~mm}$ $(\mathrm{n}=1)$. Dorsal surface of cranium with 2 large setae posteriorly, near median line (Fig. 31); cardo with 2 lateral setae; antennae, in addition to the basal and 2 apical antennomeres, with 3 smaller antennomeres between them. Final instar larva: unknown to me; cranium and cervix described for P. punctatus by MacLeod (1964). According to his data, it might be characterised by two unique characters within the order Neuroptera: the unique form of the tentorial crossbar with the extensive line of junction between the bilateral arms and by the presence of gula on ventral surface of cranium.

Material examined. Three first instar larvae (mounted on slides): Mexico: Chiapas, April 25, 1966, O.S. Flint leg., det. Six first instar larvae (mounted on slides): Mexico, San Antonio, Tex lot 64-20926, eggs on Chamaedorea sp. Palm fronds, Aug. 07, 1964, O.S. Flint reared the larvae from eggs. All larvae deposited in National Museum of Natural History, Washington 


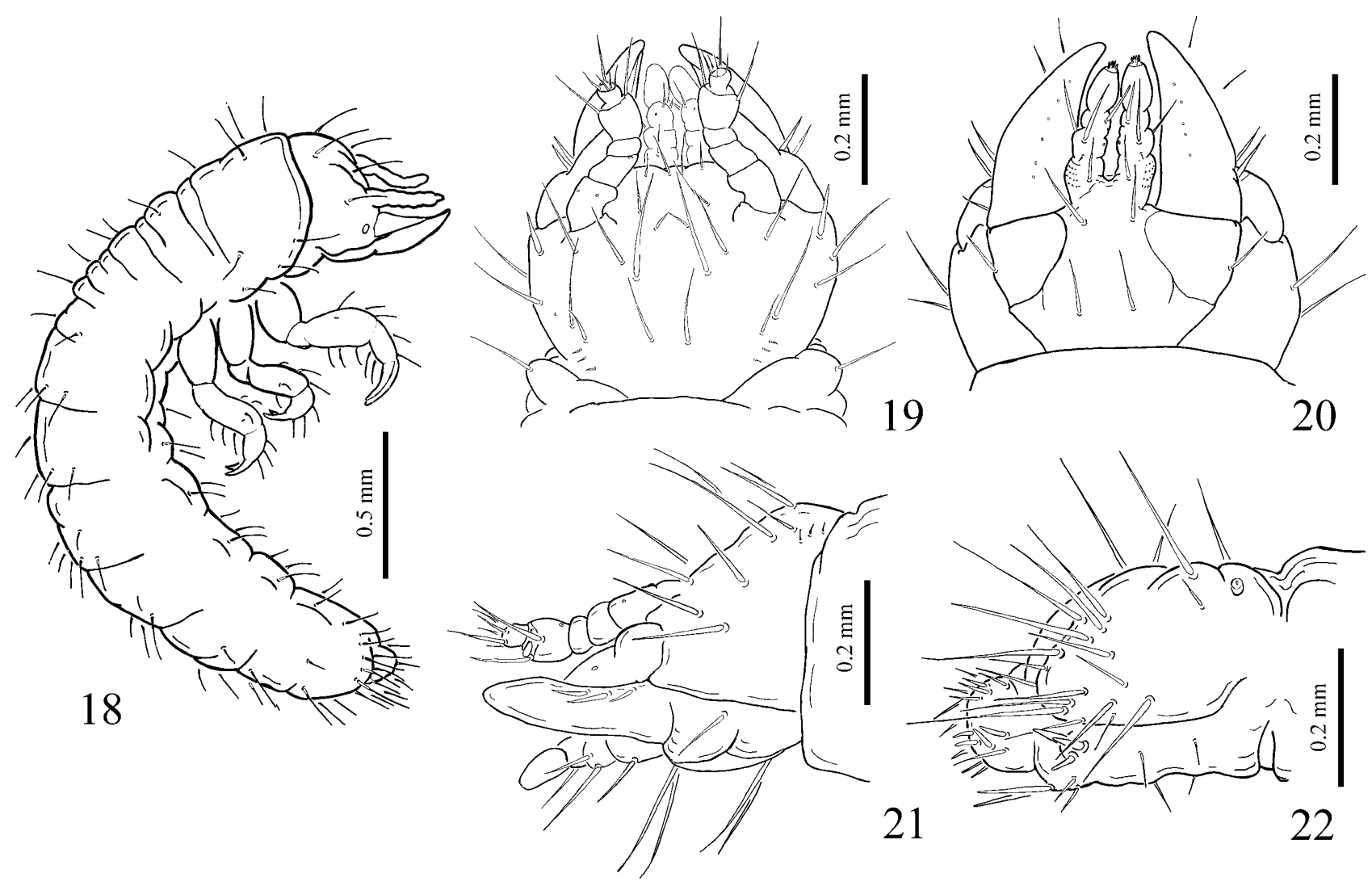

Figs 18-22: Ithone fusca, first instar larva. 18 - habitus, lateral; 19 - head, dorsal; 20 - head, ventral; 21 - head, lateral; 22 eighth abdominal segment, lateral.

D.C. Remarks. According to the data on the distribution of species of the members of the family Polystoechotidae (Oswald, 1998), these larvae can belong either to Polystoechotes punctatus or an undescribed species. Some notable differences between the larvae I studied and those of Polystoechotes punctatus described by Welch (1914) should be noted. The larvae I studied do not have dorsal longitudinal sutures, they have three (not five) similar smaller antennomeres between the basal antennomere and the two apical ones, and they do not have eye-spots.

\section{DISCUSSION}

Larvae of Ithonidae and Polystoechotidae are easily distinguished within the order Neuroptera, however the majority of their distinctive characters are plesiomorphies. Apparently, the C-shaped bodies of older instar larvae and the phytosuccivorous habits of larvae (Faulkner, 1990; Aspöck et al., 2001) might be synapomorphic characters unique to a clade comprising at least Ithone and Oliarces. The states of these two characters for Polystoechotidae larvae are unknown. MacLeod (1964) studied the mature larvae of $P$. punctatus, however his unpublished thesis includes no description of their body shape. It is reasonable to assume that the $P$. punctatus larvae were not C-shaped as in Ithone or Oliarces, otherwise MacLeod would have mentioned it. Other potential morphological synapomorphies of Ithonidae and Polystoechotidae were first described by MacLeod (1964: 152) for the mature larvae of Ithone and Polystoechotes and are found in those of Oliarces: the mandibles have exceptionally broad bases and markedly thickened apical parts
(Figs 5, 14); antennal curvature is fixed and rather characteristic in shape; ocular area reduced or absent; cardo and stipes are markedly enlarged with stipes much larger than the cardo; presence of gula (Polystoechotes) or some traces of gular sclerotisation (Ithone, Oliarces).

Larvae of Ithone have numerous unique autapomorphic characters, such as C-shaped first instar larva with reduced abdominal segments IX and $\mathrm{X}$; fused tibiotarsus; maxillae directed markedly dorsally. As a result, at least the first instar larvae of Oliarces are more similar to those of Polystoechotidae than to those of Ithone. These are, however, almost exclusively plesiomorphic similarities. Consequently, it is currently unclear whether larval morphology supports the clade Ithone + Oliarces, or the representative of Polystoechotidae might eventually be found to be more closely related to one of these two genera. There is at least one indication of this possibility, noted by MacLeod (1964: 151), namely the cranium in mature larvae of Ithone and Polystoechotes is vertically markedly enlarged and therefore its vertical depth exceeds its antero-posterior length (Fig. 8). Contrary to this, the cranium in Oliarces is markedly more depressed dorsolaterally (Fig. 13), which is apparently a plesiomorphy. On the other hand, mature larvae of Polystoechotes and Oliarces are similar in their widely spaced labial palpi, while in Ithone the labial palpi are close together.

Based on larval morphological characters very little can be said about the sister-group for the clade comprising Ithonidae and Polystoechotidae. The most recent phyloge- 


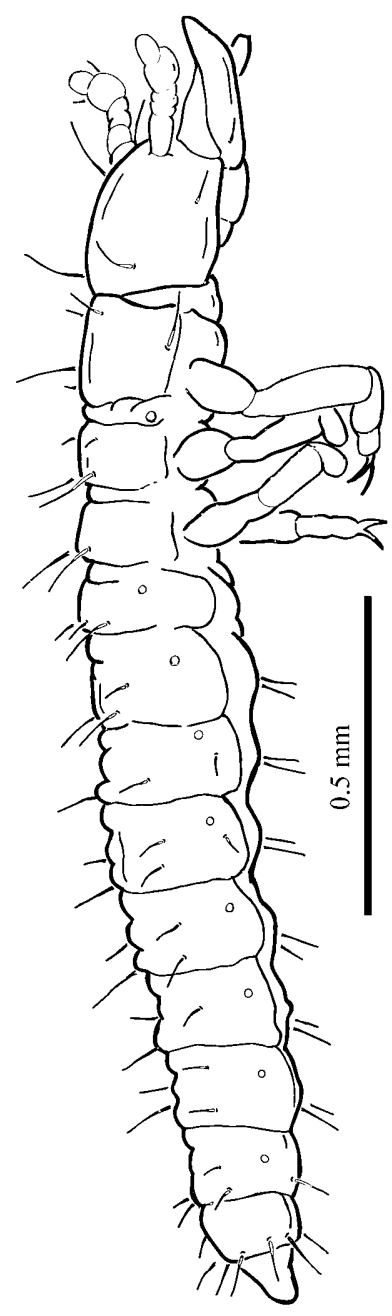

23
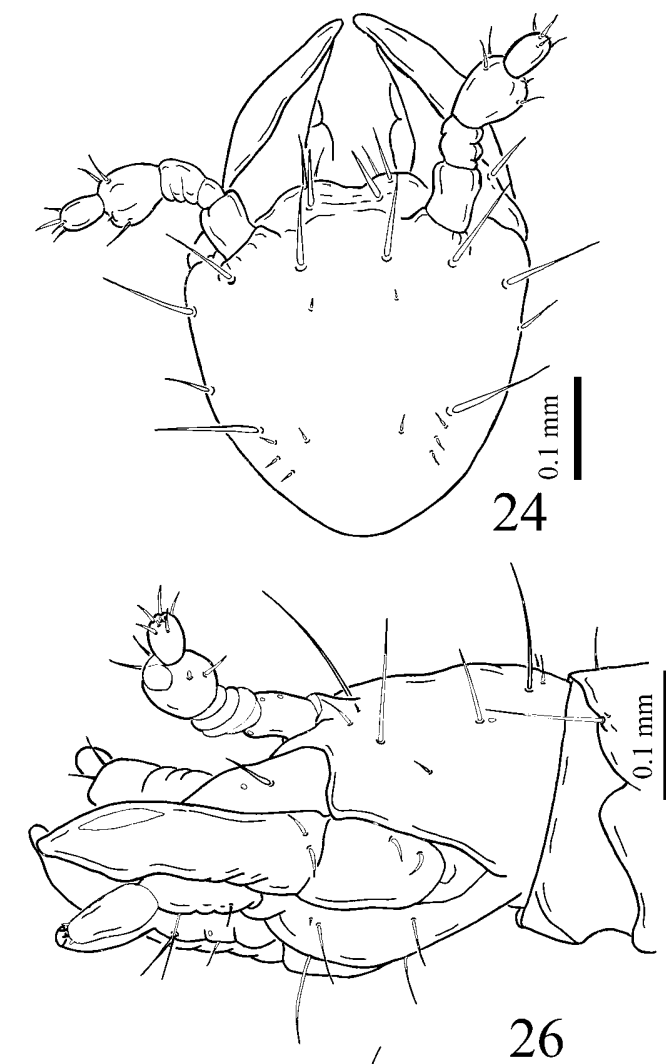

26

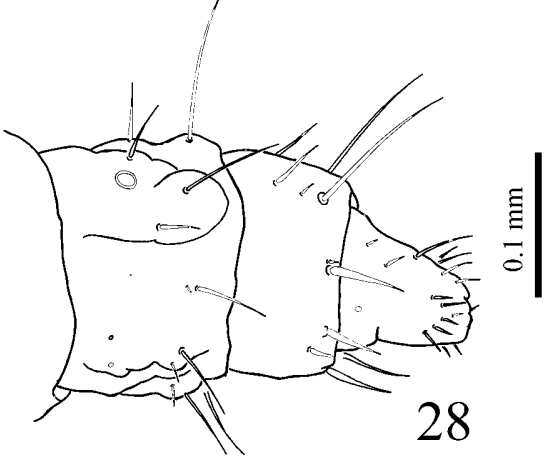

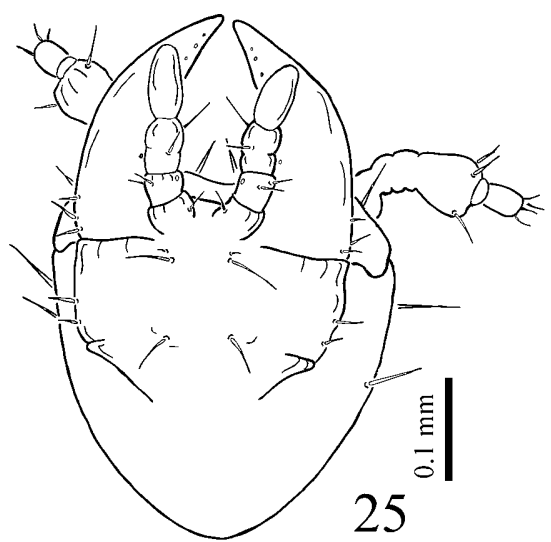
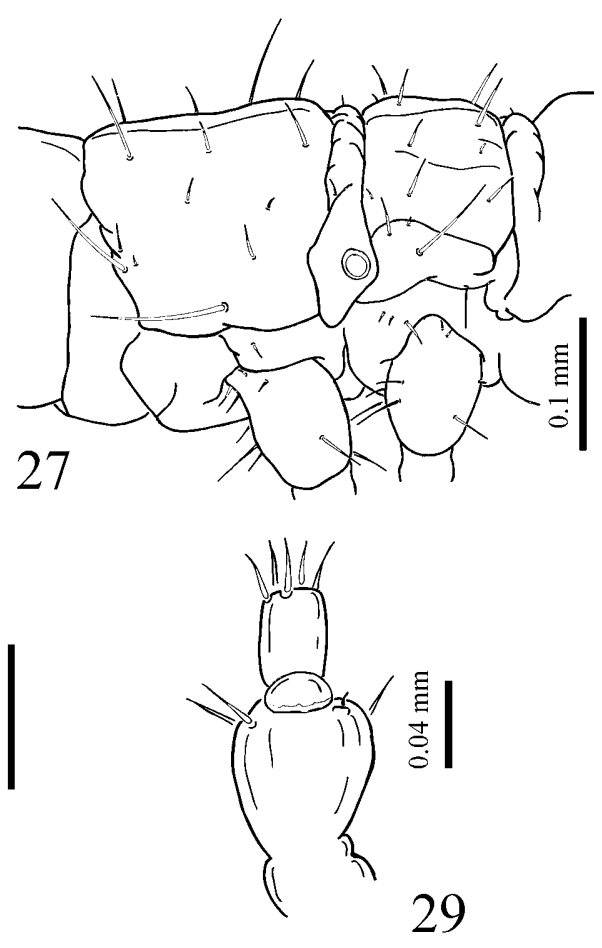

Figs 23-29: Oliarces clara, first instar larva. 23 - habitus, lateral; 24 - head, dorsal; 25 - head, ventral; 26 - head, lateral; 27 pro- and mesothorax, left lateral; 28 - eighth, ninth and tenth abdominal segments, lateral; 29 - two penultimate antennomeres of left antenna, ventral.

netic hypothesis (Aspöck, 2002; Aspöck et al., 2001, 2003; for other opinions see Sziráki, 1996; Kubrakiewicz et al., 1998; Winterton, 2003) proposed that these two families (possibly with the addition of Rapismatidae) form a sister-group to the rest of the Hemerobiiformia clade consisting of (Chrysopidae + Osmylidae) + (Hemerobiidae $+(($ Coniopterygidae + Sisyridae $)+$ (Dilaridae + (Mantispidae + (Rhachiberothidae + Berothidae))))). Three larval synapomorphies were used to support this sister-group relationship (Aspöck et al., 2001): cephalic capsule ventrally open, mainly constructed by parts of maxillae; cardines longer than half the length of the cranium; and cervix cushion-like. Larvae of Ithonidae and Polystoechotidae have some similarities with those of the family Dilaridae, namely no or only one pair of stemmata; body not flattened dorso-laterally; mesothoracic spiracle located on fold between prothorax and mesothorax; short and stout mandibles widened at base and tapered apically; fore legs more robust and elongated; tarsi on all legs markedly shortened; more than three larval instars. Some of these characters might be attributed to the fact that at least some representatives of both groups live and actively move in soil (Dilar turcicus Hagen, 1858; Oliarces clara, Ithone fusca), while some other characters, such as increased number of larval instars, might be considered as synapomorphies for these groups.

In the first description of grub-shaped larvae of Ithone Tillyard (1922) noted their similarities to those of the beetle superfamily Scarabaeoidea. Comparison of grubs of Ithonidae and Scarabaeoidea indicate that there are five convergent characters shared by these two groups. They are: (01.) C-shaped larval body at least in older instars; (02.) larval body round in cross-section; (03.) sclerites on thorax and abdomen reduced and body surface membranous; (04.) each thoracic and abdominal segment subdi- 


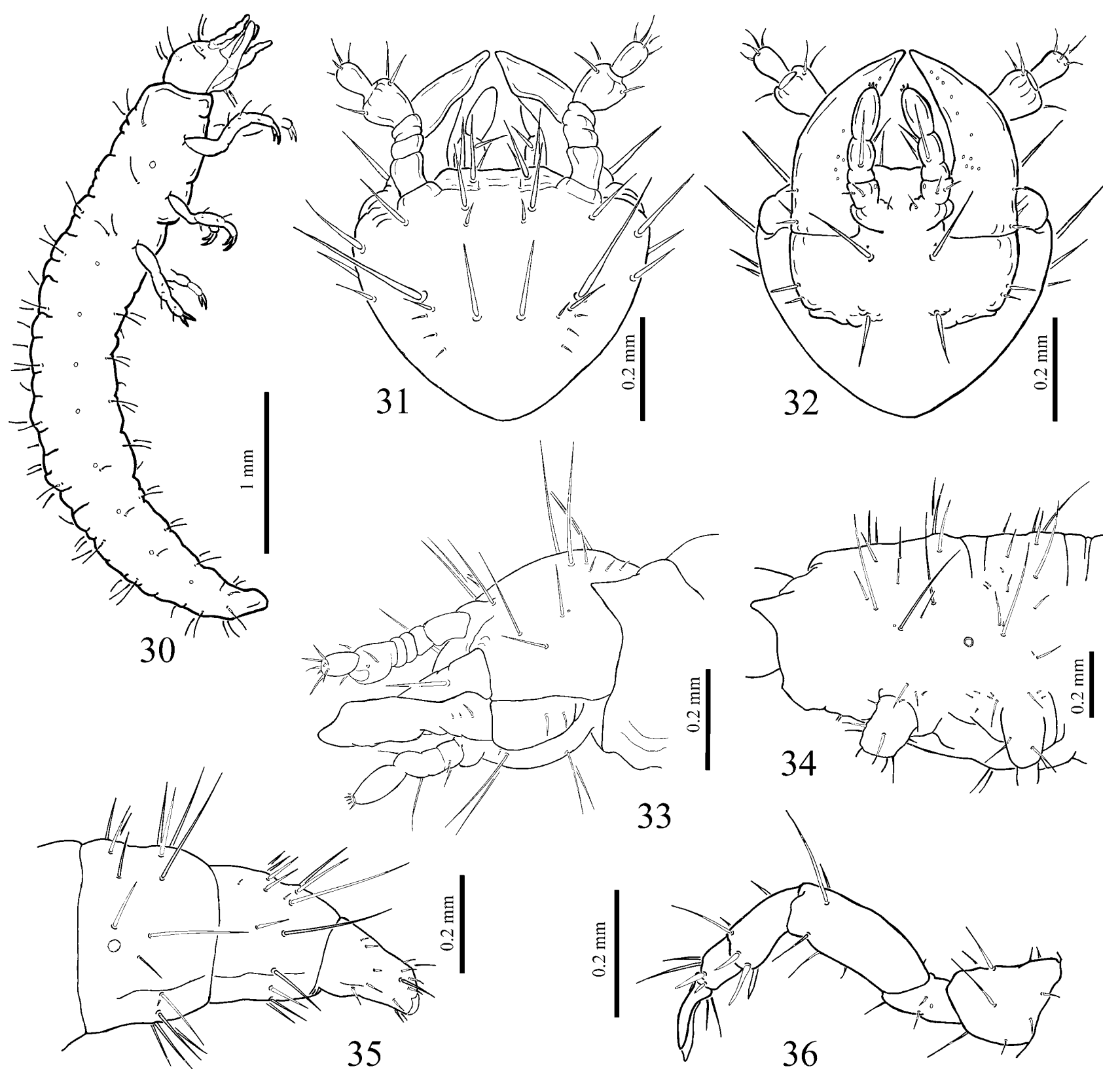

Figs 30-36: Polystoechotidae sp., first instar larva. 30 - habitus, lateral; 31 - head, dorsal; 32 - head, ventral; 33 - head, lateral; 34 - pro- and mesothorax, left lateral; 35 - eighth, ninth and tenth abdominal segments, lateral; 36 - fore leg, posterior.

vided dorsally into two (Oliarces, Geotrupidae, Bolboceratidae) or three (Ithone, Scarabaeidae, Trogidae, Hybosoridae, Glaphyridae) fleshy lobes; (05.) ventral surface of abdominal apex with a field of short and stout setae. There are, however, some characteristic larval features of Scarabaeoidea, which were not found in larvae of Ithonidae. For example, grubs of Ithonidae lack any stridulatory organs, which independently appeared in Scarabaeoidea on three different structures: mandible with maxillae; fore and middle legs, and middle and hind legs (Grebennikov et al., 2004; Grebennikov \& Scholtz, 2004).

When working with the first instar larvae of Ithone, Oliarces and Polystoechotes, I noticed that they possess a rather constant set of sensillae, in many respects similar to that described in various groups of Coleopteran larvae:
Grebennikov (2004) for Archostemata; Bousquet \& Goulet (1984) and Grebennikov \& Maddison (2004) for Carabidae; Alarie \& Balke (1999) for Dytiscidae; Ashe \& Watrous (1984) and Thayer (2000) for Staphylinidae; Kovarik \& Passoa (1993) for Histeridae; Grebennikov \& Beutel (2002) for Ptiliidae; Delgado \& Soler (1996, 1997) for Hydraenidae; and Wheeler (1990) and Kilian (1998) for Leiodidae. Consequently, it is reasonable to assume that the chaetotaxy in larval Neuroptera might be as phylogenetically informative as it is in the coleopteran groups mentioned above. Within Neuroptera, I am aware of only one attempt to designate homologous sensillae in first instar larvae (Hoffman \& Brushwein, 1992); however it was restricted to one subfamily and lacked broad comparative analysis of similar structures in other Neuropteran families. I hope that the sensillae of first instar 
larvae of Neuroptera will be eventually designated and this information used for descriptive and phylogenetic work.

\section{CONCLUDING REMARKS}

Two promising lines for research have emerged from this study. Firstly, find the older instar larvae of Polystoechotidae and verify whether they are grub-like and have a phytosuccivorous habit, as suggested by Aspöck et al. (2001). Secondly, undertake a widely based comparative analysis of chaetotaxy in first instar Neuroptera, or even Neuropterida larvae, as was pioneered by Hoffman \& Brushwein (1992) for Mantispinae. This could provide numerous phylogenetically valuable characters for the order.

ACKNOWLEDGEMENTS. I would like to acknowledge the help of the following people: D.K. Faulkner (San Diego, USA) for the discovery and subsequent gift of the older instar larvae of Oliarces clara and for the encouragement to undertake this project; S.J. Brooks (Natural History Museum, London, UK), N. Adams (Smithsonian Institution, National Museum of Natural History, Washington, DC, USA) and T.A. Weir (Australian National Insect Collection, Canberra, Australia) for the loan of Neuropteran larvae. B. Bateman (University of Pretoria, South Africa) linguistically corrected the MS. U. Aspöck (Wien, Austria) and J. Oswald (Texas A\&M University, USA) kindly helped with some references. D.K. Faulkner critically read the MS before submission. Funding for this project came from the A. von Humboldt Fellowship (Bonn, Germany), Visiting Fellowship from the Canadian Museum of Nature (Ottawa, Canada); Visiting Fellowship from the Field Museum of Natural History (Chicago, USA) and E. Mayr Visiting Fellowship from the Museum of Comparative Zoology (Cambridge, MS, USA).

\section{REFERENCES}

Alarie Y. \& Balke M. 1999: A study of the larva of Carabdytes upin Balke, Hendrich and Wewalka (Coleoptera: Adephaga: Dytiscidae), with comments on the phylogeny of the Colymbetinae. Coleopt. Bull. 53: 146-154.

Ashe J.S. \& Watrous L.E. 1984: Larval chaetotaxy of Aleocharinae (Staphylinoidea) based on a description of Atheta coriarica Kraatz. Coleopt. Bull. 38(2): 165-179.

AspöcK U. 1993: Geklärtes und Ungerklärtes im System der Neuroptera (Insecta: Holometabola). Mitt. Dt. Ges. Allgem. Angew. Entomol. 8: 451-456.

AsPöcK U. 2002: Phylogeny of the Neuropterida (Insecta: Holometabola). Zool. Scr. 31(1): 51-55.

Aspöck U., Apsöck H. \& Haring E. 2003: Phylogeny of the Neuropterida - morphological evidence and the molecular advocatus diaboli. Entomol. Abh. 61: 157-158.

Aspöck U., Plant J.D. \& NemeschKal H.L. 2001: Cladistic analysis of Neuroptera and their systematic position within Neuropterida (Insecta: Holometabola: Neuropterida: Neuroptera). Syst. Entomol. 26: 73-86.

BARNARD P.C. 1981: The Rapismatidae (Neuroptera): montane lacewings of the oriental region. Syst. Entomol. 6(2): 121-136.

Bousquet Y. \& Goulet H. 1984: Notation of primary setae and pores on larvae of Carabidae (Coleoptera: Adephaga). Can. J. Zool. 62: 573-588.

Delgado J.A. \& Soler A.G. 1996: Morphology and chaetotaxy of the first-instar larva of Hydraena (Phothydraena) hernandoi
Fresneda and Lagar (Hydraenidae). Koleopt. Rdsch. 66: 147-154.

Delgado J.A. \& Soler A.G. 1997: Morphology and chaetotaxy of larval Hydraenidae (Coleoptera) I: genus Limnebius Leach, 1815 based on a description of Limnebius cordobanus d'Orchymont. Aquat. Insects 19: 37-49.

FAULKNER D.K. 1990: Current knowledge of the biology of the moth-lacewing Oliarces clara Bank (Insecta: Neuroptera: Ithonidae). In Mansell M.W. \& Aspöck H. (eds): Advances in Neuropterology. Proceedings of the Third International Symposium on Neuropterology. Berg En Dal, Kruger National Park, R.S.A., 1988, pp. 197-203.

Grebennikov V.V. 2004: Review of larval morphology of beetles of the suborder Archostemata (Insecta: Coleoptera), including first-instar chaetotaxy. Eur. J. Entomol. 101: 273-292.

Grebennikov V.V. \& Beutel R.G. 2002: Morphology of the minute larva of Ptinella tenella, with special reference to effects of miniaturisation and the systematic position of Ptiliidae (Coleoptera: Staphylinoidea). Arthropod Struct. Dev. 31: $157-172$.

GrebenNikov V.V. \& Maddison D.R. 2004: Phylogenetic analysis of Trechitae (Coleoptera: Carabidae) based on larval morphology, with description of first-instar Phrypeus and a key to genera. Syst. Entomol. 29: 000-000.

Grebennikov V.V. \& Scholtz C.H. 2003: Larvae of Dascillidae (Coleoptera): morphological study and discussion on their proposed relationships to Scarabaeoidea and Eulichadidae. Insect Syst. Evol. 34: 29-39.

Grebennikov V.V. \& Scholtz C.H. 2004: Basal phylogeny of Scarabaeoidea (Insecta: Coleoptera) inferred from larval morphology. Invert. Syst. 18: 321-348.

Grebennikov V.V., Ballerio A. \& Scholtz C.H. 2002: Larva and pupa of Cyphopisthes descarpentriesi Paulian (Coleoptera: Scarabaeoidea: Ceratocanthidae) and their phylogenetic implications. Austr. J. Entomol. 41: 367-374.

Grebennikov V.V., Ballerio A., Ocampo F.C. \& Scholtz C.H. 2004: Larvae of Ceratocanthidae and Hybosoridae (Coleoptera: Scarabaeoidea): study of morphology, phylogenetic analysis and evidence of paraphyly of Hybosoridae. Syst. Entomol. 29: in press.

Hoffman K.M. \& Brushwein J.R. 1992: Descriptions of the larvae and pupae of some North American Mantispinae (Neuroptera: Mantispidae) and development of a system of larval chaetotaxy for Neuroptera. Trans. Am. Entomol. Soc. 118: 159-196.

KILIAN A. 1998: Morphology and phylogeny of the larval stages of the tribe Agathidiini (Coleoptera: Leiodidae: Leiodinae). Ann. Zool. (Warszawa) 48: 125-220.

Kovarik P.W. \& PASsoa S. 1993: Chaetotaxy of larval Histeridae (Coleoptera: Hydrophiloidea) based on a description of Onthophilus nodatus LeConte. Ann. Entomol. Soc. Am. 86: 560-576.

Kubrakiewicz J., Jedrzejowska I. \& Bilinski S.M. 1998: Neuropteroidea - different ovary structure in related groups. Folia Histochem. Cytobiol. 36: 179-187.

MacLeod E.G. 1964: A Comparative Morphological Study of the Head Capsule and Cervix of Larval Neuroptera (Insecta). Unpublished PhD Thesis, Department of Biology, Harvard University, Cambridge, Massachusetts, iii +528 pp.

Oswald J.D. 1998: Rediscovery of Polystoechotes gazullai Navás (Neuroptera: Polystoechotidae). Proc. Entomol. Soc. Wash. 100: 389-394.

PEnNy N.D. 1996: A remarkable new genus and species of Ithonidae from Honduras (Neuroptera) J. Kansas Entomol. Soc. 69: 81-86. 
RIEK E.F. 1974: The Australian moth-lacewings (Neuroptera: Ithonidae). J. Australian Entomol. Soc. 13: 37-54.

Scholtz C.H. \& Grebennikov V.V. 2004: Scarabaeoidea. In Beutel R.G. \& Leschen R.A.B. (eds): Handbook of Zoology. Vol. 3. Gruyter, Berlin, in press.

SzIRÁKI Gy. 1996: Female internal genitalia of Megalithone tillyardi Riek, 1974 with comments on the systematic position of the neuropterous families (Neuroptera: Ithonidae). Folia Entomol. Hung. 57: 277-284.

TAUBER C.A. 1991: Order Neuroptera. In Stehr F.W. (ed.): Immature Insects. Vol. 2. Kendall/Hunt, Dubuque, Iowa, pp. 126-143.

ThaYer M.K. 2000: Glypholoma larvae at last: phylogenetic implications for basal Staphylinidae? (Coleoptera: Staphylinidae: Glypholomatinae). Invertebr. Tax. 14: 741-754.

Tillyard R.J. 1922: The life-history of the Australian mothlacewing, Ithone fusca Newman (Order Neuroptera, Planipennia). Bull. Entomol. Res. 13: 205-223.
Welch P.S. 1914: The early stages of the life history of Polystoechotes punctatus Fabr. Bull. Brooklyn Entomol. Soc. 9: $1-6$.

WHEELER Q.D. 1990: Morphology and ontogeny of postembryonic larval Agathidium and Anisotoma (Coleoptera: Leiodidae). Am. Mus. Novit. 2986: 1-46.

WIESENBORN W.D. 1999: High seasonal rainfall precedes Oliarces clara Banks (Neuroptera: Ithonidae) spring emergence. Pan-Pac. Entomol. 74(4): 217-222.

WINTERTON S.L. 2003: Molecular phylogeny of Neuropterida with emphasis on the lacewings (Neuroptera). Entomol. Abh. 61: $158-160$.

WithYCOMBE C.L 1925: Some aspects of the biology and morphology of the Neuroptera. With special reference to the immature stages and their possible phylogenetic significance. Trans. Entomol. Soc. Lond. 15: 303-411.

Received June 5, 2003; revised March 12, 2004; accepted April 14, 2004 